\title{
Dietary habits, physical activity and diabetes perception among patients with type 2 diabetes mellitus in Tabuk City, Saudi Arabia
}

\author{
Nadiyah Abdullah Al-Mountashiri ${ }^{1}$, Amal Mohammad AL-Zhrani ${ }^{1}$, Shereen Fawzy Hafez Ibrahim², Hyder \\ Othman Mirghani ${ }^{3}$
}

${ }^{1}$ Medical Student, Faculty of Medicine, University of Tabuk, Tabuk, Saudi Arabia

${ }^{2}$ MD, Assistant Professor, Medical Department, Faculty of Medicine, University of Tabuk, Tabuk, Saudi Arabia

${ }^{3}$ MD, Professor of Medical Microbiology \& Immunology, Faculty of Medicine, University of Tabuk, Saudi Arabia

\section{Type of article: Original}

\begin{abstract}
Background: Medical nutritional therapy is an important aspect of diabetes care, there is an increasing awareness of breakfast skipping, late dinner and meal contents on diabetes control.

Aim: To assess dietary habits, physical activity and diabetes perception among patients with type 2 diabetes.

Methods: This case-control study was conducted among patients with diabetes mellitus at the diabetes center in Tabuk City, Saudi Arabia during the period from March through June 2017. One hundred patients with type 2 diabetes and 150 control subjects were interviewed to collect demographic data regarding, breakfast skipping, late dinner intake, and fruit, vegetables, sweet food, and fast food consumption. Diabetic patients' perception of their disease was also assessed. (If diabetes is serious, it can be prevented and reversible). Data were analyzed by SPSS version 20 using Chi-square and independent-samples t-test.

Results: In the present study, body mass index (BMI) $(\mathrm{p}<0.001)$, fast food consumption $(\mathrm{p}<0.001)$, fruit consumption $(\mathrm{p}=0.004)$, and breakfast skipping $(\mathrm{p}<0.001)$ were higher among patients with diabetes compared to controls. No differences were found regarding the level of exercise, smoking, late dinner intake and diabetes perception. A significant statistical difference was observed between poor and accepted control regarding sweet food intake $(\mathrm{p}=0.046)$ and exercise $(\mathrm{p}=0.017)$.

Conclusion: Patients with type 2 diabetes had higher BMI, and were more likely to skip breakfast, consume less fast food and more fruits than control subjects. More physical activity and less sweet food consumption was observed among patients with accepted glycemic control.
\end{abstract}

Keywords: Breakfast skipping, Late dinner, Type 2 diabetes, Saudi Arabia

\section{Introduction}

Worldwide, $6 \%$ of the population are affected by diabetes mellitus and the projection for the year 2030 is 438 million (1). With Asian countries suffering the bulk of the total diabetes epidemic, the Kingdom of Saudi Arabia is among the countries with the highest prevalence of diabetes mellitus (23.1\%) (2). People diagnosed with diabetes, on average, have medical healthcare expenditures that are ten times higher $(\$ 3,686$ vs. $\$ 380)$ than what expenditures would be in the absence of diabetes (3). The American Diabetes Association recommends tight glycemic control as an essential strategy for the prevention of microvascular complication of diabetes mellitus. The tight glycemic control is achieved through medications and lifestyles modifications (4). Inadequate physical activity accompanied by poor dietary habits are associated with the development of obesity and type 2 diabetes mellitus. Adoption of a friendly diet and adoption of moderate physical activity are essential not only for the prevention and treatment of diabetes mellitus but also in maintaining physical and mental health $(5,6)$. Exercise is associated with lower cardiovascular disease, chronic kidney disease, sepsis, pneumonia, influenza mortality, and all-cause mortality in patients with diabetes mellitus. Higher training programs may be warranted for patients with diabetes than currently

\section{Corresponding author:}

Nadiyah Abdullah Al-Mountashiri, Faculty of Medicine, University of Tabuk, Tabuk, Saudi Arabia.

Tel.: +966501660278, Email: nadiaabdulla666@gmail.com

Received: July 02, 2017, Accepted: July 28, 2017, Published: September 2017

iThenticate screening: July 18, 2017, English editing: August 17, 2017, Quality control: September 04, 2017

(C) 2017 The Authors. This is an open access article under the terms of the Creative Commons Attribution-NonCommercialNoDerivs License, which permits use and distribution in any medium, provided the original work is properly cited, the use is non-commercial and no modifications or adaptations are made. 
provided for non-diabetics (7). Apart from weight reduction in patients with type 2 diabetes, exercise has been shown to reduce both fasting and postprandial plasma sugar (8). Smoking, a major source of reactive oxygen species, is associated with higher glycated hemoglobin, while fruit and vegetable consumption is related to improved redox status (9). Medical nutrition therapy is an essential component of patients with type 2 diabetes, eating a diet high in fiber including fruit and vegetables is recommended by most guidelines (10). Fruits are shown to reduce inflammation and endothelial dysfunction, and through their antioxidant properties, they could reduce cardiovascular disease and cancer (10). Previous literature concluded the association of fast food consumption, obesity, and type 2 diabetes mellitus (11). The majority of patients with type 2 diabetes mellitus are not meeting the recommended glycemic targets even in developed countries, with deleterious consequences. The undesirable glycemic control is mainly through deficiency of nutritional knowledge and non-compliance with healthy lifestyles which are important for patients with diabetes in the short and long term (12). Regarding the long-term effect of lifestyle interventions to prevent diabetes in the China Da Qing Diabetes Prevention Study: a 20-year follow-up study show that group-based lifestyle interventions over 6 years can prevent or delay diabetes for up to 14 years after the active intervention (13). Previous studies have demonstrated the efficacy of lifestyle intervention for the prevention of type 2 diabetes mellitus (14). Thus, we conducted this research to study the lifestyle effects on diabetes control among patients with type 2 diabetes in Tabuk, Saudi Arabia.

\section{Material and Methods}

This case-control study was conducted at the diabetes center in the King Fahad Specialist Hospital, Tabuk City, Saudi Arabia during the period from March 2017 through June 2017. One hundred consecutive patients with the diagnosis of type 2 diabetes mellitus according to the American Diabetes Association guidelines4 and came for routine follow-up were enrolled (patients with type 1 diabetes and those recently diagnosed were not included). To minimize the socioeconomic differences, 150 healthy control subjects were randomly chosen in a ratio of 1:1 from the co-patients. The participants were invited to sign a written informed consent, then interviewed by the researchers using a structured questionnaire to collect data on age, sex, level of education, income, if the patient had received education about diabetes, adherence to a healthy diet, frequency of sugar, fast food, and fruit and vegetable consumption in the last month. Also included in the questionnaire were the level of exercise as defined by the American Diabetes Association (30 minutes daily for at least five days a week) (4), medication types, compliance to medications and reasons for not taking them, self-measurement of blood glucose and the level of blood sugar, diabetes complications, smoking, whether diagnosed with psychiatric disorders, and family history of diabetes mellitus. The participants were also asked to assess their knowledge regarding: if type 2 diabetes mellitus is dangerous, if it can be prevented or cured and if adherence to a healthy diet and exercise could control and prevent diabetes. The participants were also asked whether social isolation, marital conflicts or psychiatric problems can be associated with diabetes. The most recent $\mathrm{HbA1c}$ was collected from the patients' records to assess the degree of glycemic control, and those with HbAlc of $\leq 8$ were regarded as accepted controlled (14). The weight and height of all the participants were measured (using the apparatus: ae ADAM, UK, model: MDW-250L, HCODE\#: DWS 001) and the body mass index (BMI) was calculated. The weight was measured without shoes or heavy clothes and the height was measured in the standing position. The ethical committees of both the Medical College, University of Tabuk and King Fahad Hospital approved the research. The Statistical Package for Social Sciences IBM@ SPSS $\odot$ version 20 (IBMC Corp, Armonk, NY, USA) was used for data analysis. A comparison was undertaken between diabetic patients and control subjects and patients with accepted and poor glycemic control, the Chi-square test was used to compare non categorical data and independent-samples t-test for quantitative data. A p-value of $<0.05$ was considered significant.

\section{Results}

There were 100 patients with type 2 diabetes and 150 control subjects, the majority (58\%) of diabetic patients were in the age group 45-64 years compared to control subjects (64\% in the range 20-34) with no significant difference $(\mathrm{p}=0.260)$ (Table 1$)$. The majority $(71 \%)$ of patients with diabetes received basic education versus $22 \%$ of controls, with no significant difference $(\mathrm{p}=0.454)$. No significant statistical difference was found regarding the income which was 3,000-6,000 Riyals in $67 \%$ of diabetic patients vs. $44.7 \%$ of healthy controls $(\mathrm{p}=0.185$ ). A total of $43 \%$ of patients received health education regarding diabetes, while $60.7 \%$ of control subjects had health education $(\mathrm{p}=0.506)$ (Table 1). The BMI was $32.5 \pm 6.94 \mathrm{~kg} / \mathrm{m}^{2}$ among patients with diabetes and $26.34 \pm 5.22$ in controls with a significant difference $(\mathrm{p}<0.001), 2 \%$ of patients with diabetes consume fast food regularly vs. $21.3 \%$ of controls with a significant difference ( $<0.001$ ). Sugar consumption was observed in $43 \%$ of patients with diabetes vs. $38.6 \%$ of control subjects $(\mathrm{p}=0.494)$, a significant difference was observed between patients and controls regarding the regular consumption of fruit and vegetables $(27 \%$ vs. $12.6 \%)(\mathrm{p}=0.004)$. But, no significant differences were evident 
between patients and control subjects regarding exercise (12\% vs. $13.3 \%$; $=0.757)$, smoking $(17 \%$ vs. $14.6 \%$; $\mathrm{p}=0.618)$, psychiatric diseases ( $27 \%$ vs. $20.6 \%$; $\mathrm{p}=0.245)$, and family history of type 2 diabetes $(\mathrm{p}=0.217)$.

In the present study, $76 \%$ of control subjects and $71.3 \%$ of patients with diabetes thought that that diabetes was a dangerous disease with no significant difference ( $\mathrm{p}=0.414), 92 \%$ and $88.7 \%$ of control subjects and diabetic patients reported that diabetes mellitus was a preventable disease with no significant difference $(\mathrm{p}=0.389)$, while only $29 \%$ of control subjects and $22.6 \%$ of patients with type 2 diabetes knew that diabetes mellitus was a curable disease $(\mathrm{p}=0.258)$. It is interesting to know that $54 \%$ of diabetic patients skip breakfast consumption vs. $10 \%$ of control subjects with a significant statistical difference $(\mathrm{p}<0.001)$. Table 2 depicted the comparison between patients with type 2 diabetes and healthy control subjects. In the current data, no significant statistical difference was found between patients with accepted and poor glycemic control regarding breakfast skipping ( $26 \%$ vs. $28 \%)(\mathrm{p}=0.854)$, late dinner consumption ( $2 \%$ vs. $5 \%)(\mathrm{p}=0.262)$, and regular consumption of fast food $(2 \%$ vs. $0 \%)(\mathrm{p}=0.145)$. Table 2 illustrates the comparison between diabetic patients with poor and accepted glycemic control.

Table 1. Basic characteristics of patients with diabetes and control subjects

\begin{tabular}{|c|c|c|c|c|}
\hline \multicolumn{2}{|l|}{ Character } & Controls $(n=150)$ & Diabetes $(n=100)$ & p-value \\
\hline \multirow[t]{5}{*}{ Age (year) } & $20-34$ & $96(64 \%)$ & $10(10 \%)$ & \multirow[t]{5}{*}{$0.260^{1}$} \\
\hline & $35-44$ & $19(12.7 \%)$ & $15(15 \%)$ & \\
\hline & $45-54$ & $19(12.7 \%)$ & $30(30 \%)$ & \\
\hline & $55-64$ & $7(4.7 \%)$ & $28(28 \%)$ & \\
\hline & $>65$ & $9(6 \%)$ & $17(17 \%)$ & \\
\hline \multirow[t]{2}{*}{ Sex } & Males & $52(52 \%)$ & $97(64.6 \%)$ & \\
\hline & Females & $48(48 \%)$ & $53(35.4 \%)$ & \\
\hline \multirow[t]{2}{*}{ Education } & Basic education & $33(22 \%)$ & $71(71 \%)$ & \multirow[t]{2}{*}{0.454} \\
\hline & High education & $117(78 \%)$ & $39(39 \%)$ & \\
\hline \multirow[t]{2}{*}{ Income } & Not satisfactory & $83(55.3 \%)$ & $33(33 \%)$ & \multirow[t]{2}{*}{0.185} \\
\hline & Satisfactory & $67(44.7 \%)$ & $67(67 \%)$ & \\
\hline \multicolumn{2}{|c|}{ Barrier to meals } & $17(11.3 \%)$ & $13(13 \%)$ & 0.676 \\
\hline \multicolumn{2}{|c|}{ Health education } & $91(60.7 \%)$ & $43(43 \%)$ & 0.506 \\
\hline
\end{tabular}

1: One way ANOVA

Table 2. A comparison between diabetic patients and control subjects

\begin{tabular}{|l|l|l|l|}
\hline Character & Diabetes & Control & $\mathrm{p}$-value \\
\hline BMI $\left(\mathrm{kg} / \mathrm{m}^{2}\right)$ & $32.5 \pm 6.94$ & $26.34 \pm 5.22$ & $<0.001$ \\
\hline Regular fast food intake & $2(2 \%)$ & $32(21.3 \%)$ & $<0.001$ \\
\hline Regular sweets intake & $43(43 \%)$ & $58(38.6 \%)$ & 0.494 \\
\hline Fruits and vegetables consumption & $27(27 \%)$ & $19(12.6 \%)$ & 0.004 \\
\hline Regular exercise & $12(12 \%)$ & $20(13.3 \%)$ & 0.757 \\
\hline Smoking & $17(17 \%)$ & $22(14.6 \%)$ & 0.618 \\
\hline Psychiatric diseases & $27(27 \%)$ & $31(20.6 \%)$ & 0.245 \\
\hline Family history of diabetes & $74(74 \%)$ & $100(66.7 \%)$ & 0.217 \\
\hline Is diabetes dangerous & $76(76 \%)$ & $107(71.3 \%)$ & 0.414 \\
\hline Can diabetes be cured & $29(29 \%)$ & $34(22.6 \%)$ & 0.258 \\
\hline Is diabetes preventable & $92(92 \%)$ & $133(88.7 \%)$ & 0.389 \\
\hline Can lifestyles prevent diabetes & $93(93 \%)$ & $123(82 \%)$ & 0.013 \\
\hline Health education can prevent diabetes & $76(76 \%)$ & $128(85.3 \%)$ & 0.062 \\
\hline Marital conflicts lead to diabetes & $87(87 \%)$ & $114(76 \%)$ & 0.032 \\
\hline Social isolation can leads to diabetes & $54(54 \%)$ & $89(59.3 \%)$ & 0.404 \\
\hline Breakfast skipping & $54(54 \%)$ & $15(10 \%)$ & $<0.001$ \\
\hline Late dinner & $7(7 \%)$ & $4(2.7 \%)$ & 0.831 \\
\hline
\end{tabular}


http://www.ephysician.ir

Table 3. A comparison between accepted and poor controlled patients with diabetes

\begin{tabular}{|l|l|l|l|}
\hline Character & Poor control $(\mathrm{n}=49)$ & Accepted control $(\mathrm{n}=51)$ & $\mathrm{p}$-value \\
\hline Breakfast skipping & $26(26 \%)$ & $28(28 \%)$ & 0.854 \\
\hline Late dinner & $2(2 \%)$ & $5(5 \%)$ & 0.262 \\
\hline Fast food & $2(2 \%)$ & $0(0 \%)$ & 0.145 \\
\hline Sugar & $26(26 \%)$ & $17(17 \%)$ & 0.046 \\
\hline Fruits intake & $13(13 \%)$ & $14(14 \%)$ & 0.917 \\
\hline Exercise & $2(2 \%)$ & $10(10 \%)$ & 0.017 \\
\hline Smoking & $6(6 \%)$ & $11(11 \%)$ & 0.215 \\
\hline Psychiatric disease & $10(10 \%)$ & $17(17 \%)$ & 0.146 \\
\hline Self-monitoring & $33(33 \%)$ & $30(30 \%)$ & 0.253 \\
\hline
\end{tabular}

\section{Discussion}

The present study presented a sample of Saudi patients with type 2 diabetes with poor physical activity, low fruit and vegetable consumption, and high regular sweet food intake. The current data reflect the shift from the friendly Mediterranean diet towards Western lifestyles. Previous literature recommended that obese patients with type 2 diabetes should not restrict fruit consumption because it had no effect on weight loss, waist circumference, or HbAlc (16). Furthermore, previous studies concluded the beneficial effects of a diet rich in whole grains, legumes, fruits and vegetables, and fish on $\mathrm{HbAlc}$, body weight, low density lipoproteins, high density lipoproteins improvement, and oxidative stress (5). In the current study, cigarette smoking was found in $17 \%$ of patients with diabetes, cigarettes smoking is a major source of reactive oxygen radicals and could negatively affect glycemic control and interpretation of the HbAlc results (9). The adherence to the American Diabetes Standards of care for the consumption of a diet rich in fiber, the avoidance of sugary sweetened beverages, carbohydrate intake from legumes, whole grains, and fruits and vegetables is highly recommended as it could decrease the HbAlc by $0.5-2 \%$ (4). Physical activity of 30 minutes five times a week, and the interruption of prolonged sitting with short bouts of physical activity every 30 minutes is strongly advised. Breakfast skipping effects on diabetes mellitus is controversial, some studies reported the association of breakfast skipping with insulin resistance, increasing weight, and hyperglycemia (17), while others concluded favorable effects of whole grains and fiber consumption in breakfast on glycemic control (18). A recent controlled trial found that the consumption of a high protein breakfast attenuates the postprandial glucose response while it does not magnify the response to the second meal (the second meal phenomenon) (19). In the present study, breakfast skipping was more common among diabetic patients than control subjects with no significant statistical difference between patients with poor and accepted glycemic control. The present findings are in agreement with Uemura et al. (20) who observed that breakfast skipping increased the risk of type 2 diabetes irrespective of lifestyle and basal fasting plasma sugar and BMI. In the current study, no significant statistical difference was found between patients with type 2 diabetes and control subjects regarding late dinner consumption, with no difference between accepted and poor controlled diabetic patients, similarly a recent study conducted among South-Asian Canadian (21) concluded similar observations. The current findings of higher $\mathrm{HbA} 1 \mathrm{c}$ among patients who consumed sweet food and low physical activity are in agreement with the current literature (4). In the present study, the majority of the participants perceived that diabetes mellitus, although a morbid disease, could be prevented and cured with the adoption of healthy lifestyle and health education. The positive attitude requires more empowerment through organized health education programs at the level of health institutes and the governmental level to prevent the deleterious consequence of this serious disease. The current data showed that more than two thirds of patients with type 2 diabetes did not receive health education and nearly the same number of the patients were not meeting the American Diabetes Association targets for HbA1c, similar studies conducted in Saudi Arabia (22) concluded that only $24 \%$ of diabetic patients are meeting the glycated hemoglobin targets. Furthermore, despite the majority of patients self-monitoring their blood sugar, it was not translated in lower glycated hemoglobin A plausible explanation is that the patient may not be familiar with what to do with the results of their blood sugar. The high glycated hemoglobin and BMI, the sedentary lifestyles, and the poor dietary habits are alarming, more effort is strongly recommended to prevent the serious consequences of obesity and overweight and the microvascular complications of diabetes mellitus through healthier lifestyles.

\section{Conclusions}

The current study showed that people with type 2 diabetes had higher BMI, were not reaching the HbA1c targets, consumed sweeter foods, exercised less, and were more likely to skip breakfast. The limitations of the study are the 
relatively small size of the study sample and that the study was conducted at a single diabetes center. Further, larger multi-center studies focusing on the amount, timing, and glycemic index of meals are highly recommended.

\section{Acknowledgments:}

The present research was conducted at the Diabetes Center, King Fahad Specialist Hospital, Tabuk, Saudi Arabia. The research was self-funded and not supported by any organization or institute. We would like to acknowledge Dr. Yasin Ibrahim, Assistant Professor of Community Medicine for statistical analysis.

\section{Conflict of Interest:}

There is no conflict of interest to be declared.

\section{Authors' contributions:}

All authors contributed to this project and article equally. All authors read and approved the final manuscript.

\section{References:}

1) International Diabetes Federation, Middle East, and North Africa. 2015.

2) AL-Nozha MM, Al-Maatouq MA, Al-Mazrou YY, Al-Harthi SS, Arafah MR, Khalil MZ, et al. Diabetes in Saudi Arabia. Saudi Med J. 2004; 25(11): 1603-10. PMID: 15573186.

3) Alhowaish AK. Economic costs of diabetes in Saudi Arabia. J Family Community Med. 2013; 20(1): 1-7. doi: $10.4103 / 2230-8229.108174$.

4) American Diabetes Association. Lifestyle Management. Diabetes Care. 2017; 40(Suppl 1): S33-43. doi: $10.2337 / \mathrm{dc} 17-\mathrm{S} 007$.

5) Khemayanto H, Shi B. Role of Mediterranean diet in prevention and management of type 2 diabetes. Chin Med J (Engl). 2014; 127(20): 3651-6. PMID: 25316244.

6) Kopp M, Steinlechner M, Ruedl G, Ledochowski L, Rumpold G, Taylor AH. Acute effects of brisk walking on affect and psychological well-being in individuals with type 2 diabetes. Diabetes Res Clin Pract. 2012; 95(1): 25-9. doi: 10.1016/j.diabres.2011.09.017. PMID: 21995867.

7) Williams PT. Reduced total and cause-specific mortality from walking and running in diabetes. Med Sci Sports Exerc. 2014; 46(5): 933-9. doi: 10.1249/MSS.0000000000000197. PMID: 24968127, PMCID: PMC4157907.

8) Sukla P, Shrivastava SR, Shrivastava PS. A longitudinal study to assess the impact of exercise on clinical, biochemical, and anthropometric parameters among the type 2 diabetes patients of South India. Avicenna J Med. 2015; 5(1): 16-20. doi: 10.4103/2231-0770.148504. PMID: 25625085, PMCID: PMC4296392.

9) Vlassopoulos A, Lean ME, Combet E. Influence of smoking and diet on glycated haemoglobin and 'prediabetes' categorisation: a cross-sectional analysis. BMC Public Health. 2013; 13: 1013. doi: 10.1186/14712458-13-1013. PMID: 24499114, PMCID: PMC4029457.

10) Christensen AS, Viggers L, Hasselström K, Gregersen S. Effect of fruit restriction on glycemic control in patients with type 2 diabetes--a randomized trial. Nutr J. 2013; 12: 29. doi: 10.1186/1475-2891-12-29. PMID: 23497350, PMCID: PMC3599615.

11) Marlatt KL, Farbakhsh K, Dengel DR, Lytle LA. Breakfast and fast food consumption are associated with selected biomarkers in adolescents. Prev Med Rep. 2015; 3: 49-52. doi: 10.1016/j.pmedr.2015.11.014. PMID: 26844187, PMCID: PMC4733061.

12) Li Y, Xu M, Fan R, Ma X, Gu J, Cai X, et al. The Effects of Intensive Nutrition Education on Late MiddleAged Adults with Type 2 Diabetes. Int J Environ Res Public Health. 2016; 13(9). pii: E897. doi: 10.3390/ijerph13090897. PMID: 27618080, PMCID: PMC5036730.

13) Li G, Zhang P, Wang J, Gregg EW, Yang W, Gong Q, et al. The long-term effect of lifestyle interventions to prevent diabetes in the China Da Qing Diabetes Prevention Study: a 20-year follow-up study. Lancet. 2008; 371(9626): 1783-9. doi: 10.1016/S0140-6736(08)60766-7. PMID: 18502303.

14) Dunbar JA. Diabetes Prevention in Australia: 10 Years Results and Experience. Diabetes Metab J. 2017; 41(3): 160-7. doi: 10.4093/dmj.2017.41.3.160. PMID: 28537055, PMCID: PMC5489495.

15) Brown AF, Mangione CM, Saliba D, Sarkisian CA. Guidelines for improving the care of the older person with diabetes mellitus. J Am Geriatr Soc. 2003; 51(5 Suppl Guidelines): S265-80. PMID: 12694461.

16) Christensen AS, Viggers L, Hasselström K, Gregersen S. Effect of fruit restriction on glycemic control in patients with type 2 diabetes--a randomized trial. Nutr J. 2013; 12: 29. doi: 10.1186/1475-2891-12-29. PMID: 23497350, PMCID: PMC3599615. 
17) Cahill LE, Chiuve SE, Mekary RA, Jensen MK, Flint AJ, Hu FB, et al. Prospective study of breakfast eating and incident coronary heart disease in a cohort of male US health professionals. Circulation. 2013; 128(4): 337-43. doi: 10.1161/CIRCULATIONAHA.113.001474. PMID: 23877060, PMCID: PMC3797523.

18) Maki KC, Phillips-Eakley AK, Smith KN. The Effects of Breakfast Consumption and Composition on Metabolic Wellness with a Focus on Carbohydrate Metabolism. Adv Nutr. 2016; 7(3): 613S-21. doi: 10.3945/an.115.010314. PMID: 27184288, PMCID: PMC4863265.

19) Park YM, Heden TD, Liu Y, Nyhoff LM, Thyfault JP, Leidy HJ, et al. A high-protein breakfast induces greater insulin and glucose-dependent insulinotropic peptide responses to a subsequent lunch meal in individuals with type 2 diabetes. J Nutr. 2015; 145(3): 452-8. doi: 10.3945/jn.114.202549.

20) Uemura M, Yatsuya H, Hilawe EH, Li Y, Wang C, Chiang C, et al. Breakfast Skipping is Positively Associated With Incidence of Type 2 Diabetes Mellitus: Evidence From the Aichi Workers' Cohort Study. J Epidemiol. 2015; 25(5): 351-8. doi: 10.2188/jea.JE20140109. PMID: 25787236, PMCID: PMC4411234.

21) Sandhu SK, Tang TS. When's dinner? Does timing of dinner affect the cardiometabolic risk profiles of South-Asian Canadians at risk for diabetes. Diabet Med. 2017; 34(4): 539-42. doi: 10.1111/dme.13081. PMID: 26802477.

22) Al Harbi TJ, Tourkmani AM, Al-Khashan HI, Mishriky AM, Al Qahtani H, Bakhiet A. Adherence to the American Diabetes Association standards of care among patients with type 2 diabetes in primary care in Saudi Arabia. Saudi Med J. 2015; 36(2): 221-7. doi: 10.15537/smj.2015.2.9603. PMID: 25719589, PMCID: PMC4375702. 